treatment adjustment, and thresholds to seek medical attention. The findings of Tan et al. ${ }^{5}$ also support the findings of previous studies describing increased confidence in asthma management with AAP provision. But an important question remains, namely: does improved confidence translate into better clinical outcomes for children with asthma? Even though this was not the main purpose of this study it would have strengthened the study's conclusions if the reported benefits of having a WAAP could have been shown to be linked to improved clinical outcomes for the child. We hope that future studies will try and address this aspect.

There are several other interesting areas that remain poorly explored in the literature. Once the child has left the community and/or hospital setting, how do caregivers utilise the AAP with respect to medication adherence and decision-making for treatment and medical review during asthma episodes? How do clinicians utilize AAPs with the intended user? This aspect is of particular relevance in paediatric asthma, since AAP development should focus on optimising the caregiver's understanding of their child's asthma management. The increasing role of IT-based communication should not be ignored, and presents exciting opportunities to improve these aspects. In the interim, it is vital that health professionals continue to provide AAPs containing clear and concise information - in conjunction with appropriate education - to assist children with asthma and their caregivers in developing self-management skills. ${ }^{11}$

Conflicts of interest The authors declare that they have no conflicts of interest in relation to this article.

Commissioned article; not externally peer-reviewed; accepted 30th April 2013; online 24th May 2013

c 2013 Primary Care Respiratory Society UK. All rights reserved http://dx.doi.org/10.4104/pcrj.2013.00049

Prim Care Respir J 2013; 22(2): 144-145

\section{References}

1. Ducharme FM, Zemek, RL, Chalut D, et al. Written action plan in pediatric emergency room improves asthma prescribing, adherence and control. Am J Repir Crit Care Med 2011;183:195-203

http://dx.doi.org/10.1164/rccm.201001-01150C

2. ISSAC, Global Report Asthma 2011, www.globalasthmareport.org

3. Rank M, Volcheck G, James T, Ashokakumar M, Kaiser G. Formulating an effective and efficient written asthma action plan. Mayo Clinic Proceedings 2008:83:11. http://dx.doi.org/10.4065/83.11.1263

4. Castro M, Kraft M. Clinical Asthma, Chapter 52 Development, implementation and evaluation of an asthma management plan, 2008, Mosby, Philadelphia

5. Tan N, Chen Z, Soo W, Ngoh A, Tai B. A questionnaire survey on the effects of written asthma action plan on caregivers' management of children with asthma. Prim Care Respir J 2013;22(2):188-94. http://dx.doi.org/10.4104/pcrj.2013.00040

6. Cicutto L, Madeley C, MacPherson A. Perspectives of end user of asthma action plans. Am J Respir Crit Care Med 2010;181:A4302.

7. Klok T, Kaptien A, Duiverman E, Brand P. High inhaled corticosteroids adherence in childhood asthma: the role of medication beliefs. Eur Respir J 2012;40:1149-55. http://dx.doi.org/10.1183/09031936.00191511

8. Reddel H. Action needed on asthma plans. Prim Care Respir J 2011;20(2):116-17. http://dx.doi.org/10.4104/pcrj.2011.00051

9. Ring $\mathrm{N}$, Pinnock $\mathrm{H}$, Wilson $\mathrm{C}$, et al. Understanding what asthma plans mean: a linguistic analysis of terminology used in published texts. Prim Care Respir J 2011; 20(2):170-7. http://dx.doi.org/10.4104/pcrj.2011.00012

10. Yin H, Gupta R, Tomopoulos S, et al. Readability, suitability and characteristics of asthma action plans: examination of factors that may impair understanding. Pediatrics 2013;131:1-11. http://dx.doi.org/10.1542/peds.2012-0612

11. Mosnaim $G$. Do we have evidence that pediatric written asthma action plans really work? Ann Allergy, Asthma and Immunol 2011;107:187-8. http://dx.doi.org/10.1016/j.anai.2011.07.005

\title{
Evaluation of patients with symptoms of chronic lung disease in primary care
}

\section{See linked article by Lamprecht et al. on pg 195}

\section{*Guy B Marks ${ }^{1,2}$}

1 Clinical Professor and Head, Respiratory and Environmental Epidemiology, Woolcock Institute of Medical Research, Sydney, Australia

2 Senior Staff Specialist Physician, Department of Respiratory Medicine, Liverpool Hospital, Sydney, Australia

* Correspondence: Professor Guy B Marks, PO Box M77

Missenden Road PO, NSW 2050, Australia

Tel: +61291140466 Fax: +61291140412

E-mail: guy.marks@sydney.edu.au

In this issue of the PCRJ, Lamprecht and colleagues have drawn attention to the vexing problem of diagnosing COPD in primary care. ${ }^{1}$ Their study highlights the problem of failing to identify and diagnose patients with COPD in this setting. However, it also demonstrates an alternative problem: incorrectly attaching the label of COPD to patients who do not have the disease. Of course, the key to accurate diagnosis of COPD - as defined by the Global Initiative for Chronic Obstructive Lung Disease $(G O L D)^{2}$ - is correct performance and interpretation of spirometry. Lamprecht et al. show us that, although accurate diagnosis of COPD was more likely in patients who reported having performed a lung function test, it was by no means a guarantee of accurate diagnosis. This report leaves open the critical question of whether enhanced lung function testing in primary care is likely to lead to improved outcomes for patients with chronic lung disease. Do we need to develop and evaluate new strategies for appropriate targeting of therapeutic strategies for chronic lung disease in the primary care setting?

The fact that COPD is underdiagnosed in primary care, and in the community at large, is well established in several studies ${ }^{3-6}$ and has become an article of faith within the respiratory community. However, this is unsurprising given that many people in the general population who meet the spirometric definition for persistent airflow obstructive 
(that is, a low $\mathrm{FEV}_{1} / \mathrm{FVC}$ ratio) do not have symptoms and are unlikely to be assessed for, or diagnosed with, any disease. As there is no evidence that specific therapeutic intervention is beneficial for patients with asymptomatic airflow obstruction, many of these "undiagnosed" cases are not disadvantaged by not having been diagnosed with COPD. More relevant are the patients with symptoms or disability attributable to aifflow obstruction - particularly those who have sought medical care for this problem - who have not been diagnosed. I am not aware of published data on the population prevalence of undiagnosed symptomatic COPD, although this information could feasibly be derived from the Burden of Obstructive Lung Disease (BOLD) study.

The converse to the under-diagnosis problem is over-diagnosis. In Salzburg, $48 \%$ of all people who reported a COPD diagnosis did not have spirometric evidence of persistent airflow obstruction when tested. ${ }^{1}$ This problem has been less widely studied, but in south-west Sydney, Australia, Zwar et al. found that only $58 \%$ of patients whom GPs identified as having COPD had spirometry consistent with this diagnosis. ${ }^{7}$ A further $4 \%$ had reversible airflow obstruction consistent with asthma, and $20 \%$ had other spirometric abnormalities, mainly restriction. However, $18 \%$ of these patients had entirely normal spirometry. Both studies raise the concern that patients have been exposed to treatments they do not need (with the attendant costs and risks of adverse effects) and have not received effective treatment for the real cause of their symptoms.

Since GOLD defines COPD in terms of spirometry, the diagnosis can only be made after correctly performing and interpreting spirometry. The observed very poor concordance between diagnosis and spirometric findings in many studies strongly implies that the diagnosis is commonly made without the benefit of correctly performed and interpreted spirometry. Although $41 \%$ of people aged 40 and over living in Salzburg reported having had lung function measured, ${ }^{1}$ as the authors point out this may not be representative of other areas where reimbursement for the procedure is not available or is less generous. The procedure is not as simple as it seems, and interpretation can be problematic. Hence, even where spirometry is performed, it may not be performed and interpreted correctly. ${ }^{8}$ Alternative models, including a centralised spirometry service ${ }^{9}$ and a telemedicine service, ${ }^{10}$ have been proposed and implemented. However, a cluster randomised controlled trial performed in general practices in Melbourne, Australia, showed that regular performance of spirometry did not improve health outcomes in patients with asthma and COPD ${ }^{11}$ - although this study did not directly assess the role of spirometry in initial diagnosis. This may explain the finding that, in the study by Lamprecht et al., among the 17 patients who reported a diagnosis of COPD and also reported that they had had a lung function test in the preceding 12 months, only $10(59 \%)$ actually had persistent airflow obstruction consistent with COPD. ${ }^{1}$ Hence, while performance of spirometry is a necessary condition for accurate diagnosis of COPD, it may not be a sufficient condition.

It remains to be seen whether accurate spirometric diagnosis of COPD in the primary care setting substantially improves outcomes for patients. Chronic lung disease in older people is a heterogeneous condition which cannot readily be classified simply as "asthma" or
"COPD" ${ }^{12} \mathrm{~A}$ diverse range of therapeutic options are available, including (but not limited to) bronchodilator therapy (both $\beta_{2}$-agonist and anti-muscarinic), inhaled and oral corticosteroids, theophylline and other phosphodiesterase inhibitors, exercise-based pulmonary rehabilitation, long-term home oxygen therapy, enhanced sputum clearance techniques, vaccination against influenza, and a range of novel therapies currently under investigation. The heterogeneity in both the disease and the therapeutic options raises the possibility that these therapies would be used most effectively and efficiently if they were targeted at particular sub-groups of patients with chronic lung disease.

We are only at the beginning of attempts to design disease management strategies in accordance with this model. M easurement of pulse oximetry to identify patients with chronic lung disease who would benefit from long-term oxygen therapy is one example. It seems likely that performing spirometry for the detection of airflow obstruction in symptomatic patients will be most useful for identifying those who will benefit from bronchodilator therapy. However, as yet there are no feasible tests to assist in targeting $\beta_{2}$-agonist and antimuscarinic inhaled therapy specifically; nor are there tests that identify who will benefit from any of the other available therapeutic options. In the absence of such tests, available therapies tend to be added to each other in a patient who remains symptomatic, even if one of more of these therapies is not actually helping.

Hence, while improving the performance and interpretation of spirometry among breathless patients who are seen in primary care is a worthwhile objective, we need further research to identify and evaluate new tests that will help primary care doctors to utilise effectively and efficiently all of the therapeutic options that are available for patients with chronic lung disease.

Conflicts of interest The author declares that he has no conflicts of interest in relation to this article.

Commissioned article; not externally peer-reviewed; accepted 15th May 2013; online 24th May 2013

(c) 2013 Primary Care Respiratory Society UK. All rights reserved http://dx.doi.org/10.4104/pcrj.2013.00054

Prim Care Respir J 2013; 22(2): 145-147

\section{References}

1. Lamprecht B, Mahringer A, Soriano JB, Kaiser B, Buist AS, Studnicka M. Is spirometry properly used to diagnose COPD? Results from the BOLD study in Salzburg, Austria: a population-based analytical study. Prim Care Respir J 2013;22(2):195-200. http://dx.doi.org/10.4104/pcrj.2013.00032

2. Global Initiative for Chronic Obstructive Lung Disease. Global strategy for the diagnosis, management and prevention of chronic obstructive pulmonary disease. (Revised 2011). 2011 [18/02/2012]; Available from: http://www.goldcopd.com/.

3. Caramori G, Bettoncelli G, Tosatto $R$, et al. Underuse of spirometry by general practitioners for the diagnosis of COPD in Italy. Monaldi Arch Chest Dis 2005; 63(1):6-12

4. Tinkelman DG, Price DB, Nordyke RJ, Halbert RJ. Misdiagnosis of COPD and asthma in primary care patients 40 years of age and over. J Asthma 2006;43(1):75-80. http://dx.doi.org/10.1080/02770900500448738

5. Bednarek M, Gorecka D, Wielgomas J, et al. Smokers with airway obstruction are more likely to quit smoking. Thorax 2006;61(10):869-73. http://dx.doi.org/10.1136/thx.2006.059071 
6. Toelle B, Xuan W, Bird T, et al. Respiratory Symptoms and Illness in Older Australians: the Burden of Obstructive Lung Disease (BOLD) Study. Med J Aust 2013;198:144-48. http://dx.doi.org/10.5694/mja11.11640

7. Zwar NA, Marks GB, Hermiz O, et al. Predictors of accuracy of diagnosis of chronic obstructive pulmonary disease in general practice. Med J Aust 2011;195:168-71.

8. Enright PL. Should we keep pushing for a spirometer in every doctor's office? Respir Care 2012;57(1):146-51;discussion 51-3.

http://dx.doi.org/10.4187/respcare.01504

9. Starren ES, Roberts NJ, Tahir M, et al. A centralised respiratory diagnostic service for primary care: a 4-year audit. Prim Care Respir J 2012;21:180-6. http://dx.doi.org/10.4104/pcrj.2012.00013

10. Burgos F, Disdier C, de Santamaria EL, et al. Telemedicine enhances quality of forced spirometry in primary care. Eur Respir J 2012;39(6):1313-18. http://dx.doi.org/10.1183/09031936.00168010

11. Abramson MJ, Schattner RL, Sulaiman ND, et al. Do spirometry and regular followup improve health outcomes in general practice patients with asthma or COPD? A cluster randomised controlled trial. Med J Aust 2010;193(2):104-09. Epub 2010/07/21

12. Gibson PG, McDonald VM, Marks GB. Asthma in older adults. Lancet 2010;376(9743):803-13. http://dx.doi.org/10.1016/S0140-6736(10)61087-2

\section{Available online at http://www.thepaj.org}

\section{Primary Care Respiratory Society UK} National Primary Care Respiratory Conference

\section{Inspiring excellence locally: navigating the path to quality respiratory care 11th-12th October 2013, Telford International Centre}

\section{CALL FOR ABSTRACTS - PCRS-UK Clinical and Scientific Abstracts 2013}

The annual PCRS-UK conference aims to showcase community-based respiratory research and innovative clinical/service developments through a series of abstract-based oral presentation sessions throughout the conference as well as a poster display in the exhibition area.

We are therefore inviting submission of abstracts for oral presentation in the research sessions, and poster submissions for display in the exhibition area, throughout the 2013 PCRS-UK conference.

\section{F250} PRIZE

for best original

abstract showing

best practice

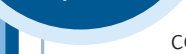

$\mathrm{CV}$ and is a chance to meet other like-minded individuals. Previous

feedback from both junior and experienced researchers has shown

that the Original research abstract presentation sessions at the

conference are stimulating, enjoyable and useful.

\section{Sharing Best Practice - the power of audit}

If you have been involved in a project which has changed practice in primary care, why not submit an abstract describing your project and its findings?

This is an opportunity for you to showcase your work share your experiences and discuss the outcomes of your work with colleagues. We are particularly keen to see the results of local or national audits which have the potential to improve outcomes for our patients in primary care.
Abstracts presented elsewhere will be accepted

\section{SUBMISSION} DEADLINE 7 JUNE 2013
For details on submission dates, how to get help, how to submit your abstract, and guidance on artwork together with notes for contributors, please log on to http://www.thepcrj.org/abstracts/

Be a part of the Conference - Share your work with the PCRS-UK The PCRS-UK is willing to offer support to those without previous experience of submitting posters

"prizes available only to entrants who are submitting original work which has not previously been published or presented at national/international meetings and conferences

The PCRS-UK is a registered charity (Charity Number: 1098117) and a company, registered in England and limited by guarantee (Company number 4298947). Registered Offices: 2 Wellington Place, Leeds, LS1 4AP

Address for Correspondence: PCRS-UK, Smithy House, Waterbeck, Lockerbie, DG11 3EY, UK Telephone: +44 (0)121 7671928

Facsimile: +44 (0)1213361914 Websites: http://www.pcrs-uk.org, http://www.thepcrj.com Email: info@pcrs-uk.org 